\title{
Expression of chitinase-3-like protein 1 in different TCM syndromes and its correlation with liver fibrosis
}

\author{
Hong Li, Xiaoli Xu, Ting Yi, Tingting Zheng, Tong Yan \\ Hepatology Department of Integrated Traditional Chinese and Western Medicine, Changzhou Third People's Hospital, Changzhou, China \\ Contributions: (I) Conception and design: $\mathrm{H} \mathrm{Li}, \mathrm{X} \mathrm{Xu}$, T Yan; (II) Administrative support: X Xu; (III) Provision of study materials or patients: H Li, \\ T Yan; (IV) Collection and assembly of data: H Li; (V) Data analysis and interpretation: H Zhou; (VI) Manuscript writing: All authors; (VII) Final \\ approval of manuscript: All authors. \\ Correspondence to: Tong Yan. Hepatology Department of Integrated Traditional Chinese and Western Medicine, Changzhou Third People's Hospital, \\ No. 300, Lanling North Road, Tianning District, Changzhou 213001, China. Email: czsygbk39@163.com.
}

Background We aimed to explore the expression of chitinase-3-like protein 1 (CHI3L1) in different traditional Chinese medicine (TCM) syndromes and its correlation with liver fibrosis.

Methods: A total of 95 patients with hepatitis B e antigen (HBeAg)-positive chronic hepatitis B who were diagnosed by pathological examination of liver biopsy specimens were selected as study subjects. According to different TCM syndrome types, 47 cases were divided into damp-heat moderate resistance type, and 48 cases were liver depression and spleen-deficiency type. Serum samples of the 2 groups were collected, then the levels of CHI3L1 were detected by enzyme-linked immunosorbent assay (ELISA). Hyaluronic acid (HA), laminin (LN), fibronectin (FN), collagen type IV (CIV), and N-terminal procollagen III propeptide (PIIINP) were measured by chemiluminescence. The levels of CHI3L1 was studied to explore the correlations between the 2 types of TCM syndromes and liver fibrosis.

Results: The serum CHI3L1 level of the 2 groups increased with increasing fibrosis stage and peaked at the S4 stage. The serum CHI3L1 levels of liver depression and spleen deficiency type patients in the S0-S1, S2-S3, and S4 stages were higher than those of patients with damp-heat moderate resistance type, and the difference was significant $(\mathrm{P}<0.01)$. The levels of HA, LN, FN, CIV, and PIIINP in the 2 groups increased with the increase of fibrosis stage and reached the highest level at the S4 stage. Compared to patients with damp-heat syndrome, the levels of HA, LN, FN, CIV, and PIIINP in patients with liver depression and spleen deficiency syndrome were lower, and the difference was statistically significant $(\mathrm{P}<0.05)$. There were positive correlations between CHI3L1 and HA, LN, FN, CIV, and PIIINP (all <0.05).

Conclusions: The expression level of CHI3L1 in HBeAg-positive chronic hepatitis B patients was higher than expected. The levels of CHI3L1, HA, LN, FN, CIV, and PIIINP in liver depression and spleen deficiency type patients were lower than those in damp-heat moderate resistance type patients. These findings indicated that CHI3L1 is correlated with HA, LN, FN, CIV, PIIINP liver fibrosis indexes, and the syndrome of stagnation of spleen deficiency has a better correlation.

Keywords: Chitinase-3-like protein 1 (CHI3L1); liver depression and spleen deficiency type; damp-heat moderate resistance type; hepatic fibrosis

Submitted Nov 24, 2021. Accepted for publication Jan 07, 2022.

doi: 10.21037/apm-21-3760

View this article at: https://dx.doi.org/10.21037/apm-21-3760 


\section{Introduction}

Hepatitis B virus infection is a worldwide epidemic. About $25 \%$ of patients with chronic hepatitis B will eventually suffer from decompensated cirrhosis or rapid deterioration of chronic hepatitis B. This can even lead to death due to liver failure caused by hepatocellular carcinoma, posing a significant threat to the health of people (1). In traditional Chinese medicine (TCM), Chronic hepatitis B belongs to this category because it is similar to "liver depression", "hypochondriac pain", "jaundice", and other diseases. Liver depression and spleen deficiency type, along with dampheat moderate resistance type, are the most common (2). According to the characteristics and pathogenesis of the hepatitis B virus, when the hepatic damp-heat virus invades the liver, spleen, stomach, and kidneys, the patients suffers from damp-heat or damp-heat virus (3). Hepatitis B e antigen (HBeAg)-positive chronic hepatitis $\mathrm{B}$ infection is mainly caused by pre-C region mutation and core promoter mutation. The liver tissue damage induced by this disease is severe, and the disease progresses rapidly.

Liver fibrosis refers to the abnormal hyperplasia of connective tissue in the liver caused by various pathogenic factors (4). Chitinase-3-like protein 1 (CHI3L1) is a secretory glycoprotein and is a liver-specific or highly enriched gene, which can be used as a good marker of liver disease. Some studies have shown that the hepatitis $\mathrm{C}$ virus and fibrosis are related, but the expression of CHI3 $\mathrm{L} 1$ in HBeAg-positive chronic hepatitis B fibrosis has rarely been reported $(5,6)$. TCM believes that syndrome differentiation can reflect the different development stages of the pathology of chronic hepatitis B. Our study intends to select the TCM syndrome types with good correlation between CHI3L1 and the degree of fibrosis on the basis of TCM syndrome differentiation to verify whether it can be become a reliable method for the diagnosis and staging of liver fibrosis. Therefore, in this study, we explored the expression of CHI3L1 in different TCM syndromes and its correlation with liver fibrosis. We present the following article in accordance with the MDAR reporting checklist (available at https://apm.amegroups.com/article/view/10.21037/apm$21-3760 /$ rc).

\section{Methods}

\section{Research subjects}

A total of 95 patients with HBeAg-positive chronic hepatitis B diagnosed by liver biopsy in Changzhou Third People's
Hospital from December 2016 to December 2019 were selected as the research subjects. According to the different TCM syndrome types, they were divided into 47 cases of damp-heat moderate resistance type and 48 cases of liver depression and spleen deficiency type. Among damp-heat moderate resistance type, there were 29 male patients and 18 female patients, aged from 32 to 51 years old, with an average age of $41.5 \pm 8.2$ years old. There were 32 male patients and 16 female patients, aged from 35 to 54 years old, with an average age of $44.5 \pm 7.6$ years old in liver depression and spleen deficiency type. The general data of all patients were comparable. All procedures performed in this study involving human participants were in accordance with the Declaration of Helsinki (as revised in 2013). The study was approved by the Ethics Committee of Changzhou Third People's Hospital (No.: 2018-06) and informed consent was obtained from all the patients.

\section{Inclusion criteria}

For Western medicine diagnosis, HBeAg-positive chronic hepatitis $\mathrm{B}$ patients were required to meet the diagnostic criteria of chronic hepatitis B according to the "guidelines for the prevention and treatment of chronic hepatitis B (2019)": serum hepatitis B surface antigen (HBsAg) and hepatitis B virus HBV DNA were positive for more than 6 months; serum alanine aminotransferase (ALT): $2 \times$ upper limit of normal $(\mathrm{ULN}) \leq \mathrm{ALT} \leq 10 \times \mathrm{ULN}$. For diagnosis by TCM, all patients met the diagnostic criteria of chronic hepatitis B in the standard of syndrome differentiation of TCM for viral hepatitis. According to the actual number of cases in our hospital, we selected 2 syndrome types: dampheat moderate resistance type and liver depression and spleen deficiency type.

For TCM Syndrome Differentiation Standard:

(I) Syndrome of damp-heat resistance: main symptoms: (i) lack of food and poor appetite; (ii) Bitter mouth and dry mouth; (iii) red tongue and yellow greasy coating. Secondary symptoms: (i) loose stools or uncomfortable stickiness; (ii) sleepiness and fatigue; (iii) pulse string or string slippage. Dialectical criteria: (i) those who have all the main certificates; (ii) those who have any 2 of the main certificates and 2 of the secondary certificates.

(II) Syndrome of liver depression and spleen deficiency: main symptoms: (i) flank ribs swelling and pain; (ii) abdominal distension or loose stools; (iii) light tongue, tooth marks, white coating. Secondary 
symptoms: (i) emotional depression; (ii) fatigue and fatigue; (iii) thin pulse. Dialectical criteria: (i) those who have all the main certificates; (ii) those who have 2 main certificates and 2 secondary certificates.

\section{Exclusion criteria}

Pregnant or lactating women were excluded from this study. Patients with other viral infections, abnormal thyroid function, or previous liver diseases, mental disorders, and autoimmune diseases were excluded. Those who used interferon for antiviral treatment, immunosuppression, or anticancer chemotherapy were not included. The study excluded patients with liver cancer or other cancers confirmed by biopsy.

\section{Liver biopsy}

All patients underwent ultrasound-guided percutaneous liver biopsy with $16 \mathrm{G}$ bard biopsy needles. The $1.5-2.5 \mathrm{~cm}$ liver tissues contained at least 6 hepatic portal tracts for analysis. Then, the routine specimens were fixed and embedded in alkaline paraffin for hematoxylin and eosin (HE) staining. According to the staining, the degree of liver fibrosis was divided into stages S0-S4, where S0: no fibrosis; S1: the fibrosis of the portal area was enlarged, and there was fibrosis around the sinus and in lobules; S2: fibrosis appeared around the portal area with fibrous septa and lobular structure preserved; S3: fibrous septum with lobular structure disorder, but without cirrhosis; $\mathrm{S} 4$ : cirrhosis. $\mathrm{S} \geq 2$ was defined as significant hepatic fibrosis.

\section{Blood Sample collection}

All samples were centrifuged at room temperature for $5 \mathrm{~min}$ with a radius of $5 \mathrm{~cm}$ and a rotating speed of 3,000 r/min. The supernatant was separated into an EP tube without RNase. The supernatant was centrifuged at $4^{\circ} \mathrm{C}$ for $10 \mathrm{~min}$ with a radius of $5 \mathrm{~cm}$ and a rotating speed of 12,000 r/min. The supernatant was then collected and stored in an EP tube without RNase at $-80^{\circ} \mathrm{C}$ for further use.

\section{Evaluation of liver fibrosis level}

The chemiluminescence method detected the levels of hyaluronic acid (HA), laminin (LN), fibronectin (FN), collagen type IV (CIV), and N-terminal procollagen III propeptide (PIIINP). The antibodies of HA, LN, FN, CIV, and PIIINP were coated in 96-well microplates to prepare solid phase carriers. The standard or sample was added to the microplate. HA, LN, FN, CIV, and PIIINP combined with the antibodies attached to the solid carriers. Then, biotinylated antibodies HA, LN, FN, CIV, and PIIINP were added. After washing, HRP-labeled avidin was added, and then the substrate was added after thorough washing. A luminescent light signal will be generated. The emission intensity was positively correlated with $\mathrm{HA}, \mathrm{LN}, \mathrm{FN}, \mathrm{CIV}$, and PIIINP. A chemiluminescence instrument measured the relative light unit (RLU).

\section{Statistical analysis}

SPSS 20.0 statistical software was used to analyze and process the data. The mean \pm standard deviation (SD) of different groups was compared by the independent sample $t$-test. Pearson analysis was used for correlation analysis. $\mathrm{P}<0.05$ was statistically significant.

\section{Results}

\section{Comparison of CHI3L1 levels in different syndrome types and fibrosis stages}

As shown in Table 1, the serum CHI3L1 level of the 2 groups increased with the fibrosis stage and peaked at the S4 stage. The serum CHI3L1 levels of patients with liver depression and spleen deficiency in the S0-S1, S2-S3, and S4 stages were higher than those of patients with damp-heat moderate resistance type, showing a significant difference between the 2 groups $(\mathrm{P}<0.01)$.

\section{Comparison of liver fibrosis markers in different syndrome types}

As shown in Tables 2-6, the levels of HA, LN, FN, CIV, and PIIINP in the 2 groups increased with the increase of fibrosis stage and reached the highest level at the S4 stage. Compared to patients with damp-heat syndrome, the levels of HA, LN, FN, CIV, and PIIINP in patients with liver depression and spleen deficiency syndrome were lower, and the difference was statistically significant $(\mathrm{P}<0.05)$.

\section{Correlation analysis between CHI3L1 and liver fibrosis}

As shown in Figure 1, the correlation analysis between CHI3L1, HA, LN, FN, CIV, and PIIINP demonstrated 
Table 1 Comparison of CHI3L1 levels in different syndrome types and different fibrosis stages $\left(\bar{x}_{ \pm \mathrm{s}}, \mathrm{pg} / \mathrm{mL}\right)$

\begin{tabular}{lcccc}
\hline \multirow{2}{*}{ TCM syndrome type } & $\mathrm{n}$ & \multicolumn{3}{c}{ Fibrosis stage } \\
\cline { 3 - 5 } & & $\mathrm{S} 0-\mathrm{S} 1$ & $\mathrm{~S} 2-\mathrm{S} 3$ & $\mathrm{~S} 4$ \\
\hline Damp-heat moderate resistance type & 47 & $52.36 \pm 7.69$ & $62.58 \pm 7.69$ & $153.24 \pm 20.14$ \\
$\begin{array}{l}\text { Liver depression and spleen } \\
\text { deficiency type }\end{array}$ & 48 & $60.15 \pm 12.16$ & $72.34 \pm 11.25$ & $186.44 \pm 22.46$ \\
$t$ & & 3.723 & 4.926 & 7.580 \\
$\mathrm{P}$ & & 0.001 & 0.001 & 0.001 \\
\hline
\end{tabular}

CHI3L1, chitinase-3-like protein 1; TCM, traditional Chinese medicine.

Table 2 Comparison of HA levels in different syndrome types and different fibrosis stages $\left(\bar{x}_{ \pm \mathrm{S}}, \mathrm{ng} / \mathrm{mL}\right)$

\begin{tabular}{|c|c|c|c|c|}
\hline TCM syndrome type & $\mathrm{n}$ & \multicolumn{3}{|c|}{ Fibrosis stage } \\
\hline Damp-heat moderate resistance type & 47 & $63.24 \pm 11.21$ & $75.38 \pm 13.69$ & $84.52 \pm 16.38$ \\
\hline $\begin{array}{l}\text { Liver depression and spleen } \\
\text { deficiency type }\end{array}$ & 48 & $59.63 \pm 9.68$ & $65.11 \pm 10.29$ & $72.15 \pm 12.36$ \\
\hline$t$ & & 1.676 & 4.139 & 4.161 \\
\hline
\end{tabular}

HA, hyaluronic acid; TCM, traditional Chinese medicine.

Table 3 Comparison of LN levels in different syndrome types and different fibrosis stages $\left(\bar{x}_{ \pm \mathrm{s}}, \mathrm{ng} / \mathrm{mL}\right)$

\begin{tabular}{|c|c|c|c|c|}
\hline TCM syndrome type & $\mathrm{n}$ & \multicolumn{3}{|c|}{ Fibrosis stage } \\
\hline Damp-heat moderate resistance type & 47 & $90.23 \pm 16.32$ & $96.59 \pm 15.32$ & $103.85 \pm 25.41$ \\
\hline $\begin{array}{l}\text { Liver depression and spleen } \\
\text { deficiency type }\end{array}$ & 48 & $75.33 \pm 13.42$ & $75.23 \pm 12.49$ & $91.35 \pm 19.56$ \\
\hline$P$ & & 0.001 & 0.001 & 0.008 \\
\hline
\end{tabular}

LN, laminin; TCM, traditional Chinese medicine.

Table 4 Comparison of FN levels in different syndrome types and different fibrosis stages $\left(\bar{x}_{ \pm \mathrm{s}}, \mathrm{ng} / \mathrm{mL}\right)$

\begin{tabular}{|c|c|c|c|c|}
\hline TCM syndrome type & $\mathrm{n}$ & \multicolumn{3}{|c|}{ Fibrosis stage } \\
\hline Damp-heat moderate resistance type & 47 & $96.85 \pm 11.25$ & $110.25 \pm 17.21$ & $138.52 \pm 34.25$ \\
\hline $\begin{array}{l}\text { Liver depression and spleen } \\
\text { deficiency type }\end{array}$ & 48 & $81.12 \pm 8.63$ & $92.31 \pm 11.26$ & $108.24 \pm 20.11$ \\
\hline
\end{tabular}

FN, fibronectin; TCM, traditional Chinese medicine. 
Table 5 Comparison of CIV levels in different syndrome types and different fibrosis stages $(\bar{x} \pm \mathrm{s}, \mathrm{ng} / \mathrm{mL})$

\begin{tabular}{|c|c|c|c|c|}
\hline TCM syndrome type & $\mathrm{n}$ & \multicolumn{3}{|c|}{ Fibrosis stage } \\
\hline Damp-heat moderate resistance type & 47 & $71.26 \pm 10.26$ & $79.85 \pm 11.25$ & $90.35 \pm 19.65$ \\
\hline $\begin{array}{l}\text { Liver depression and spleen } \\
\text { deficiency type }\end{array}$ & 48 & $48.26 \pm 7.35$ & $65.88 \pm 9.58$ & $72.52 \pm 14.25$ \\
\hline
\end{tabular}

CIV, collagen type IV; TCM, traditional Chinese medicine.

Table 6 Comparison of PIIINP levels in different syndrome types and different fibrosis stages $\left(\bar{x}_{ \pm \mathrm{s}}, \mathrm{ng} / \mathrm{mL}\right)$

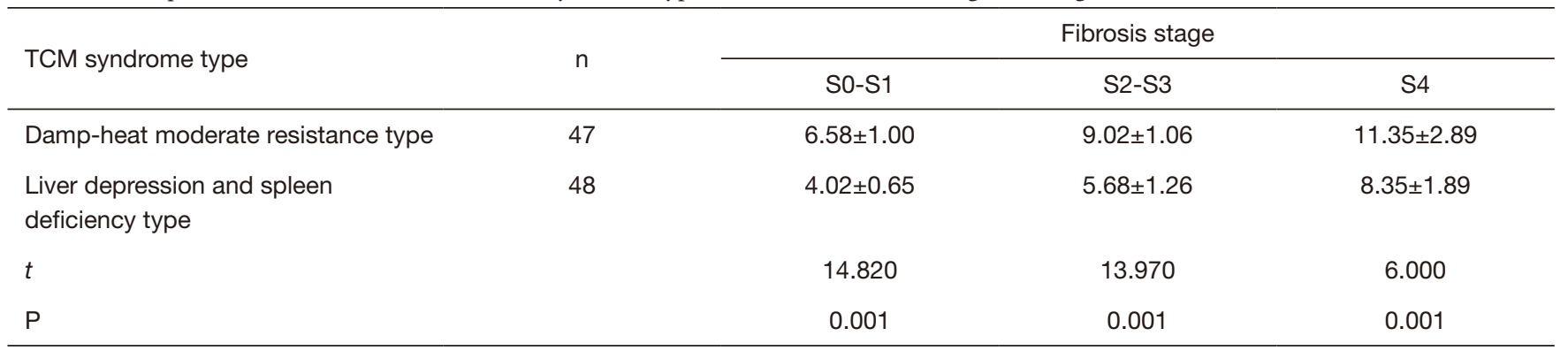

PIIINP, N-terminal procollagen III propeptide; TCM, traditional Chinese medicine.

that CHI3L1 was positively correlated with HA ( $\mathrm{r}=0.329$, $\mathrm{P}=0.001), \mathrm{LN}(\mathrm{r}=0.588, \mathrm{P}=0.001), \mathrm{FN}(\mathrm{r}=0.329, \mathrm{P}=0.001)$, CIV (r=0.298, $\mathrm{P}=0.002)$, and PIIINP ( $\mathrm{r}=0.267, \mathrm{P}=0.006)$.

\section{Discussion}

After the human body is infected with the hepatitis B virus, various immune reactions occur. The body can clear the virus through an immune response. After entering the body, the virus will be integrated into liver cells and form an immune complex. It is attacked by the body's complement system and inflammatory factors. In the process of immune killer cells removing the virus, it will also cause damage to the liver cells. In addition, a small number of hepatitis B patients develop chronic hepatitis B. This can then worsen to cirrhosis, liver failure, and even liver cancer, and the incidence of this disease is higher. The consequences are therefore not ideal $(7,8)$.

In recent years, Chinese medicine has shown unique advantages in diagnosing and treating chronic hepatitis B. Dialectical treatment is the essence of Chinese medicine. The different TCM syndromes can reflect chronic hepatitis $\mathrm{B}$ disease development, which is essential for the clinical understanding of disease progression, guiding treatment, and judging prognosis. In this study, patients with $\mathrm{HBeAg-}$ positive chronic hepatitis B were classified into TCM syndrome types. Two types were selected for investigation and research: damp-heat moderate resistance type and liver depression and spleen deficiency type.

Liver fibrosis is caused by toxins, virus infections, and alcohol abuse, among other factors. It is a standard chronic pathological marker of all kinds of liver injury. Intrahepatic inflammatory activities lead to sustained damage and repair of hepatocytes and repeated destruction and reconstruction of liver tissue structure. This eventually leads to structural changes in the liver. In the late stage, it can progress to cirrhosis. It is also an important factor affecting the prognosis of chronic liver disease (9-11). The "gold standard" for the diagnosis of liver fibrosis is liver biopsy, but this examination causes particular trauma to the body and is limited in clinical application. Therefore, further exploration of serum markers is a research hotspot in this field (12). The Chi311 gene is located on human chromosome 1q32.1, which contains 7,948 bases and 10 exons. Its sequence is highly conserved and is primarily expressed in the liver, 15-227 times that in the human 

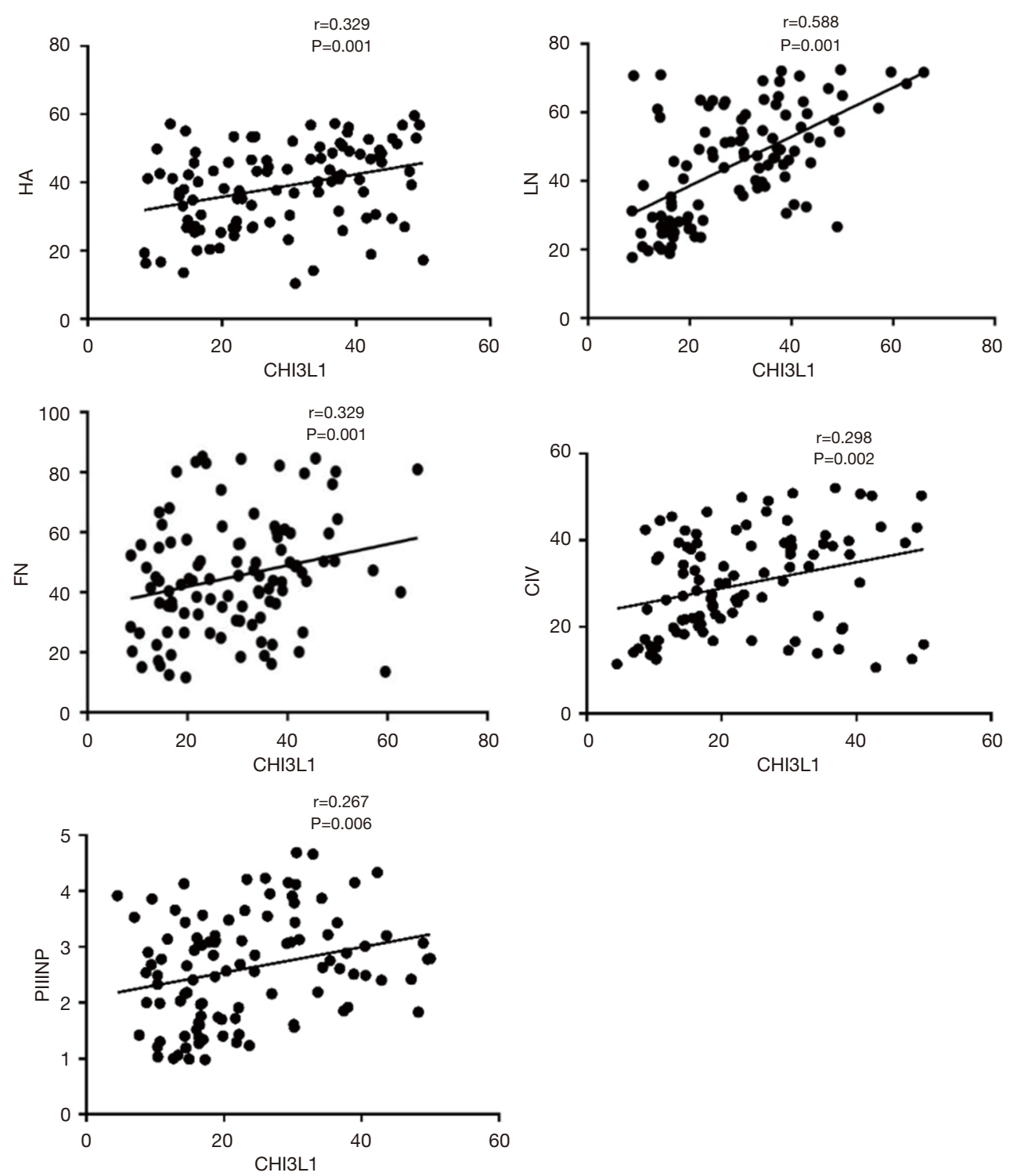

Figure 1 Correlations between chitinase-3-like protein 1 (CHI3L1) and hyaluronic acid (HA), laminin (LN), fibronectin (FN), collagen type IV (CIV), and N-terminal procollagen III propeptide (PIIINP).

brain, heart, breast, and other organs. It is also a highly liver enriched gene (13). CHI3L1 is a monomer glycosylated protein and a member of the glycohydrolase family. It has 383 amino acids and is about $40 \mathrm{kDa}$ in size. It can bind to chitosan but has no chitosanase activity, and plays an essential role in inflammation and tissue remodeling (14). Studies have shown that CHI3L1 plays a vital role in the occurrence and development of liver fibrosis $(15,16)$. It participates in the formation of liver fibrosis by activating stellate cells. By regulating part of the cell response, it promotes the production of $\mathrm{FN}$ and $\mathrm{LN}$ and engages in the development of liver fibrosis cells. In addition, as a component of the extracellular matrix, it can participate in fibrosis and forms positive feedback to signaling pathways to accelerate fibrosis. In this study, CHI3L1 was highly expressed in liver fibrosis with specificity, suggesting that it participates in this process. We also found that the serum CHI3L1 levels of patients with liver depression and spleen deficiency syndrome in the S0-S1, S2-S3, and S4 stages were higher than those of patients with damp- 
heat syndrome, indicating that its correlation with liver depression and spleen deficiency syndrome was better.

HA, LN, FN, CIV, and PIIINP are 5 suitable biomarkers for fibrosis diagnosis. HA is synthesized by intrahepatic fatstoring cells and is a crucial component of the extracellular matrix of the liver. In liver fibrosis, HA increases due to the proliferation of fibroblasts and stromal cells. In addition, the degradation ability of HA will decrease after liver damage, which further increases the level of HA in vivo (17). LN is mainly synthesized by endothelial cells and fat-storing cells in the liver and consists of a $400 \mathrm{kDa}$ cell $\alpha$ Chain and two $200 \mathrm{KD} \beta$ Chains. It is a non-collagen structural protein and one of the basement membrane components, which is positively correlated with the activity of liver fibrosis (18). In the previous study, $\mathrm{FN}$ is a high molecular weight glycoprotein with a molecular weight of about $450 \mathrm{kDa}$, which can participate in collagen metabolism, hepatocyte damage repair, and can regulate the function of the reticuloendothelial system (19). Its level is positively correlated with the degree of liver fibrosis. CIV is the main component of the basement membrane reticular structure. It is involved in adhesion and binding with collagen fibers, cell membrane receptors, and cells. However, it cannot directly participate in the formation of collagen fibers. When liver fibrosis occurs, its upregulation can be seen in the early stage, which can be used as a serum indicator for the diagnosis of liver fibrosis (20). Increased PIIINP level is related to an increase in type III procollagen synthesis. In the early stage of liver fibrosis, the synthesis of type III procollagen is active. Its level is associated with hepatitis, necrosis, and fibrosis, and is a good marker of liver fibrosis activity (21). In this study, the above indicators showed abnormally high expression in liver fibrosis. This suggests that these markers can be used to diagnose liver fibrosis, and the combination of multiple indicators can effectively improve the diagnostic value. We also found that HA, LN, FN, CIV, and PIIINP levels were highly expressed in the 2 syndrome types. Compared with those in the S0-S1, S2S3, and S4 stages, HA, LN, FN, CIV, and PIIINP levels in patients with liver depression and spleen deficiency type were lower than those of patients with damp-heat moderate resistance type, which indicated that the correlation with liver depression of spleen deficiency type was better.

In summary, the results of this study show that the expression level of CHI3L1 is higher in HBeAg-positive chronic hepatitis B patients, and there are differences in the expression levels of markers related to HBeAg-positive chronic hepatitis $\mathrm{B}$ in the liver depression and spleen deficiency type and the damp-heat moderate resistance type. The level of CHI3L1 in liver depression and spleen deficiency syndrome patients was higher than that of the damp-heat moderate resistance patients. HA, LN, FN, CIV, and PIIINP levels in the liver depression and spleen deficiency syndrome patients were lower than those of the damp-heat and moderate resistance patients. These findings show that CHI3L1 is correlated with HA, LN, FN, CIV, and PIIINP liver fibrosis indexes, and liver depression of spleen deficiency syndrome has a better correlation.

\section{Acknowledgments}

Funding: This study was supported by Science and Technology Project of Changzhou City Health and Family Planning Commission (No. ZD201815).

\section{Footnote}

Reporting Checklist: The authors have completed the MDAR reporting checklist. Available at https://apm.amegroups. com/article/view/10.21037/apm-21-3760/rc

Data Sbaring Statement: Available at https://apm.amegroups. com/article/view/10.21037/apm-21-3760/dss

Conflicts of Interest: All authors have completed the ICMJE uniform disclosure form (available at https://apm. amegroups.com/article/view/10.21037/apm-21-3760/coif). The authors have no conflicts of interest to declare.

Ethical Statement: The authors are accountable for all aspects of the work in ensuring that questions related to the accuracy or integrity of any part of the work are appropriately investigated and resolved. All procedures performed in this study involving human participants were in accordance with the Declaration of Helsinki (as revised in 2013). The study was approved by the Ethics Committee of Changzhou Third People's Hospital (No.: 2018-06) and informed consent was obtained from all the patients.

Open Access Statement: This is an Open Access article distributed in accordance with the Creative Commons Attribution-NonCommercial-NoDerivs 4.0 International License (CC BY-NC-ND 4.0), which permits the noncommercial replication and distribution of the article with the strict proviso that no changes or edits are made and the original work is properly cited (including links to both the 
formal publication through the relevant DOI and the license). See: https://creativecommons.org/licenses/by-nc-nd/4.0/.

\section{References}

1. Chuaypen N, Payungporn S, Poovorawan K, et al. Next generation sequencing identifies baseline viral mutants associated with treatment response to pegylated interferon in HBeAg-positive chronic hepatitis B. Virus Genes 2019;55:610-8.

2. Lu Y, Fang Z, Zeng T, et al. Chronic hepatitis B: dynamic change in Traditional Chinese Medicine syndrome by dynamic network biomarkers. Chin Med 2019;14:52.

3. Oyagüez I, Buti M, Brosa M, et al. Cost-Effectiveness and Clinical Impact of Antiviral Strategies of HBeAgPositive and -Negative Chronic Hepatitis B. Ann Hepatol 2017;16:358-65.

4. Fattovich G, Bortolotti F, Donato F. Natural history of chronic hepatitis B: special emphasis on disease progression and prognostic factors. J Hepatol 2008;48:335-52.

5. Wang S, Hu M, Qian Y, et al. CHI3L1 in the pathophysiology and diagnosis of liver diseases. Biomed Pharmacother 2020;131:110680.

6. Kang Q, Chen J, Luo H, et al. Decrease in Chitinase 3-Like Protein 1 Levels Reflects Improvement in Liver Fibrosis after HCV Eradication. Dis Markers 2020;2020:8539804.

7. van Bömmel F, van Bömmel A, Krauel A, et al. Serum HBV RNA as a Predictor of Peginterferon Alfa-2a Response in Patients With HBeAg-Positive Chronic Hepatitis B. J Infect Dis 2018;218:1066-74.

8. Tang LSY, Covert E, Wilson E, et al. Chronic Hepatitis B Infection: A Review. JAMA 2018;319:1802-13.

9. Seto WK, Lo YR, Pawlotsky JM, et al. Chronic hepatitis B virus infection. Lancet 2018;392:2313-24.

10. Parola M, Pinzani M. Liver fibrosis: Pathophysiology, pathogenetic targets and clinical issues. Mol Aspects Med 2019;65:37-55.

11. Bataller R, Brenner DA. Liver fibrosis. J Clin Invest

Cite this article as: $\mathrm{Li} \mathrm{H}, \mathrm{Xu} \mathrm{X}$, Yi T, Zheng T, Yan T. Expression of chitinase-3-like protein 1 in different TCM syndromes and its correlation with liver fibrosis. Ann Palliat Med 2022;11(1):217-224. doi: 10.21037/apm-21-3760
2005;115:209-18.

12. Enomoto H, Bando $\mathrm{Y}, \mathrm{Nakamura} \mathrm{H}$, et al. Liver fibrosis markers of nonalcoholic steatohepatitis. World J Gastroenterol 2015;21:7427-35.

13. Zhao T, Su Z, Li Y, et al. Chitinase-3 like-protein-1 function and its role in diseases. Signal Transduct Target Ther 2020;5:201.

14. Libreros S, Garcia-Areas R, Iragavarapu-Charyulu V. CHI3L1 plays a role in cancer through enhanced production of pro-inflammatory/pro-tumorigenic and angiogenic factors. Immunol Res 2013;57:99-105.

15. Higashiyama M, Tomita K, Sugihara N, et al. Chitinase 3-like 1 deficiency ameliorates liver fibrosis by promoting hepatic macrophage apoptosis. Hepatol Res 2019;49:1316-28.

16. Jin $\mathrm{X}, \mathrm{Fu} \mathrm{B}, \mathrm{Wu} \mathrm{ZJ}$, et al. Serum chitinase-3-like protein 1 is a biomarker of liver fibrosis in patients with chronic hepatitis B in China. Hepatobiliary Pancreat Dis Int 2020;19:384-9.

17. Gudowska M, Cylwik B, Chrostek L. The role of serum hyaluronic acid determination in the diagnosis of liver fibrosis. Acta Biochim Pol 2017;64:451-7.

18. Mak KM, Mei R. Basement Membrane Type IV Collagen and Laminin: An Overview of Their Biology and Value as Fibrosis Biomarkers of Liver Disease. Anat Rec (Hoboken) 2017;300:1371-90.

19. Younesi S, Parsian H. Diagnostic accuracy of glycoproteins in the assessment of liver fibrosis: A comparison between laminin, fibronectin, and hyaluronic acid. Turk J Gastroenterol 2019;30:524-31.

20. Lehmann J, Praktiknjo M, Nielsen MJ, et al. Collagen type IV remodelling gender-specifically predicts mortality in decompensated cirrhosis. Liver Int 2019;39:885-93.

21. Bril F, Leeming DJ, Karsdal MA, et al. Use of Plasma Fragments of Propeptides of Type III, V, and VI Procollagen for the Detection of Liver Fibrosis in Type 2 Diabetes. Diabetes Care 2019;42:1348-51. 